\title{
Influence of Longitudinal Arch of Foot on the Strength and Muscle Activity of the Abductor Hallucis in Subjects with and without Navicular Drop Sign
}

\author{
In-Cheol Jeon
}

Department of Physical Therapy, College of Life \& Health Science, Hoseo University, Asan, Korea

\begin{abstract}
Purpose: This study examined the influence of longitudinal arch on the strength and muscle activity of the abductor hallucis in the standing position in subjects with and without navicular drop signs.

Methods: A sample of 34 subjects with and without navicular drop signs between 22 and 28 years of age were enrolled in this study. The strength and muscle activity of the abductor hallucis was measured using a tensiometer. The Smart KEMA System and electromyography device was used on the subjects with and without navicular drop signs. Two groups were classified using the navicular drop test to identify the longitudinal arch of the foot. The strength of the abductor hallucis was evaluated in standing, both with and without an external arch support condition. The two-way mixed ANOVA was used. The level of statistical significance was set to $\alpha=0.05$.

Results: The strength and muscle activity of the abductor hallucis in standing was significantly higher with external arch support than that without the external arch support in the group with navicular drop signs. There was no significant difference in the abductor hallucis strength and muscle activity with and without external arch support in the subjects without navicular drop signs.

Conclusion: The strength and muscle activity of the abductor hallucis in standing can be influenced by the external arch support in the group with navicular drop signs. The strength measurement of the abductor hallucis in standing should be separately performed in conditions with and without longitudinal arch of foot.
\end{abstract}

Keywords: Abductor hallucis, Foot, Longitudinal arch; Navicular drop sign.

\section{서 론}

가로활은 체중을 지지하기 위하여 발의 내재근(intrinsic muscles)으 로 만들어진 구조로써, 체중지지상태에서 발의 내적 안정성에 기여 한다.' 또한 내재근과 외재근(extrinsic muscles) 강화운동을 통해서 발 의 안정성이 향상된다. ${ }^{2}$ 가로활 유지 훈련은 발목과 발의 만성적 통증 을 방지하고, ${ }^{3}$ 선 자세 균형을 향상시키며, ${ }^{4}$ 염좌(sprain)와 같은 근골 격계 손상을 예방하기 위하여 추천되어 왔다. ${ }^{5}$ 비정상적인 가로활을 가진 대상자는 발배뼈 하강 검사(navicular drop test)를 통해서 평가 될 수가 있는데, ${ }^{6}$ 이전 문헌들을 보면 가로활이 무너진 대상자에게는 엄지벌림근과 발등올림근의 힘이 정상그룹보다 약하다고 보고되었 다.1-3특히, 발과 발목 관절의 손상 또는 염좌를 많이 입는 대상자들 에게서 가로활이 무너져서 발생하는 편평발(pes planus), 평발(flat

Received Jul 1, 2019 Revised Aug 6, 2019

Accepted Aug 26, 2019

Corresponding author In-Cheol Jeon

E-mail jeon6984@hoseo.edu foot)과 더불어 엄지벌림근의 약화가 나타난다고 보고되었다. 5,7, 따라 서 이와 같은 비정렬적인 발은 선 자세에서 가로활이 무너진다는 특 징을 가지고 있다.

엄지벌림근은 선 자세 (standing position)에서 발의 안정성을 유지 하는데 중요한 역할을 하고, 발의 정렬을 향상시키는데 중요한 기능 을 하는 근육 중에 하나이다.910 발목 관절의 수술 후, 발의 내재근 약 화 그리고 기능적 발등 굽힘 제한들과 같은 요소는 엄지벌림근 약화 에 영향을 준다."1 선 자세에서 엄지발가락 벌림 기능을 유지하는 것 은 무지외반증의 발생을 최소화 하고, 선 자세의 발의 균형을 향상시 키기 위해 중요한 기능적 움직임이라고 볼수 있다.

가로활은 일반적으로 선 자세와, 비체중 지지 상태에서의 앉은 자세를 통해서 평가될 수 있다.69,12 이러한 보상작용의 메카니즘에 대한 충분한 이해는 엄지벌림근의 기능을 정확하게 평가하고 해석 
하는데 필수적이다.9,13 지금까지의 연구를 보면, 발의 가로활의 유 무에 따라 선 자세에서 외부적 가로활 지지 여부가 엄지벌림근의 근력에 미치는 영향을 조사한 연구는 없었다. 체중지지 상태에서 발의 가로활의 지지 유무가 엄지벌림근 근력과 근활성도에 미치는 영향을 연구하는 것은 엄지벌림근을 종합적으로 평가하기 위해 필 수적이라고 본다. ${ }^{14}$

발의 가로활은 선 자세 동안에 발의 균형과 안정성에 기여한다. 또 한 엄지벌림근은 걷기와 같은 기능적인 움직임을 하는 동안에 발목 관절과 발허리관절에서 가로활과 더불어 동적 안정성을 제공한다. 이 연구의 목적은 선 자세에서 발배뼈 하강 검사 양성그룹과 음성그 룹 간에 외부적 지지가 엄지벌림근의 근활성도와 근력에 미치는 영 향을 연구하는 것이다.

발의 가로활에 대한 평가는 발배뼈 하강 검사(navicular drop test)로 진행되었다. 이 연구의 가설은 발배뼈 하강 검사 양성반응을 보이는 그룹에서 가로활의 형성을 위해 외부적 지지를 제공해 줬을 경우 엄 지벌림근의 근력과 근활성도가 향상될 것이다. 이와는 대조적으로, 발배뼈 하강 검사 음성반응을 보이는 그룹에서는 외부적 지지 여부 에 상관없이 엄지벌림근 근력과 근활성도에 큰 차이가 없을 것이다.

이 연구에 대한 결과는 발의 가로활이 엄지벌림근에 미치는 영향 을 연구함으로써, 엄지벌림근 약화가 있을 경우, 엄지벌림근 근력 평 가뿐만 아니라, 발의 가로활 평가 역시 종합적으로 고려되어야 한다 는 관점을 통해 임상적으로 도움이 될 것이다.

\section{연구 방법}

\section{1. 연구대상}

지파워 프로그램(ver.3.1.2, Franz Faul, University of Kiel, Kiel, Germany)
을 이용해서 예비실험 대상자가 5명으로 산출되었다. 실험 참가자 산 출을 하기 위해 지파워 프로그램에서 필수요소인 power는 0.80 , alpha level은 0.05 , effect sizes는 1.39 로 진행되었다. 적어도 15 명 이상의 실험 대상자가 필요하다고 산출되었고, 대상자 탈락을 고려해 총 34 명의 대상자를 모집하였다. 34 명의 건강한 대상자(나이: $25.1 \pm 3.1$ 세, 체중: $65.7 \pm 7.6 \mathrm{~kg}$, 신장: $174.8 \pm 4.8 \mathrm{~cm}$, 남성: 20 명, 여성: 14 명)가 선정되었다 (발배뼈 하강 검사 양성 그룹: 16 명, 발배뼈 하강 검사 음성 그룹: 18 명). 제외 대상은 신경근육계, 근골격계 손상이 없고, 실험을 진행하는 동 안 신체 부위에서 통증이 발견될 경우 제외되었다. 실험 과정은 모든 대상자들에게 자세하게 설명되었고, 실험참가 동의서를 받았다.

\section{2. 실험방법}

\section{1) 실험절차}

모든 실험대상자에 있어서 양발 모두 같은 형태를 가지고 있었기 때 문에, 우세측 발의 엄지벌림근의 등척성 최대 근수축을 측정하였 다. ${ }^{15}$ 발배뼈 하강 양성그룹과 음성그룹에서 외부적 가로활 지지는 모 두 우세측으로 제공되었고, 적용한 순서는 무작위화(randomization) 하여 진행하였다. 각각의 실험대상자들은 발의 가로활에 안정성을 제공하기 위한 외부적 지지가 제공되지 않았을 때 엄지발가락을 벌 리는 연습을 한 뒤, 다시 외부적 지지가 제공되었을 때 다시 엄지발가 락을 벌리는 연습을 하였다. 이 후에 실험 절차를 정확하게 수행하기 위해서 측정자와 실험 대상자는 실제 실험을 진행하기에 앞서 1 번의 훈련을 그대로 재현해서 실시하였다. 실험대상자는 편안하게 선 자세 에서 양쪽 발로 체중 지지를 하고 측정하였다. 그 후에 등척성 최대 근 수축을 통해서 우세측 발의 엄지벌림근 근력과 근활성도를 측정 하였다. 외부적 지지가 제공되지 않았을 때 실험 대상자는 엄지발가 락을 벌리는 동작을 수행한 후에, 외부적 지지를 제공한 상태에서 다
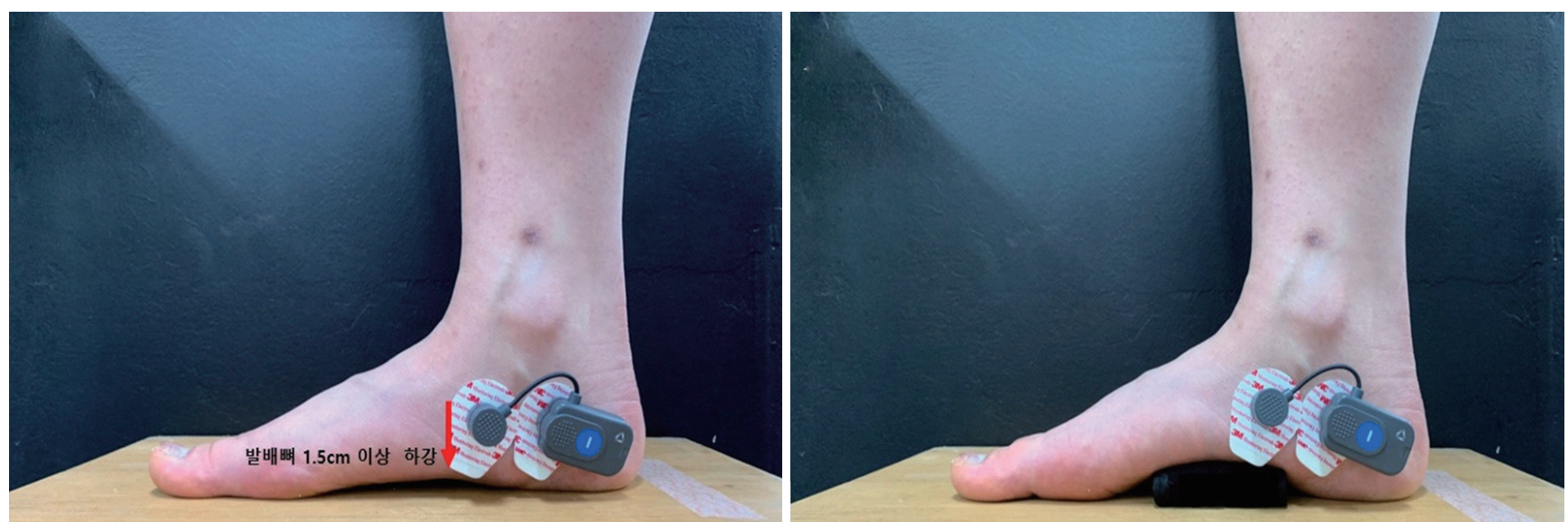

(A)

Figure 1. The group with navicular drop sign (A) without external arch support, (B) with external arch support 
시 동일하게 엄지발가락을 벌리는 동작을 수행했다. 엄지발가락을 벌리고 있는 동작은 5 초간 유지하였다. 근력 측정을 수행하면서, 엄지 벌림근의 근활성도 측정도 병행하였다. 장력계과 근전도 장비를 통 해서 측정되는 최대 근력과 근활성도 측정은 동시에 3 번 반복하여 평 균값을 사용하였다. 한번 진행한 후에는 2 분동안 휴식시간을 제공하 였다.

\section{2) 가로활 평가}

발배뼈 하강 검사를 통해 발의 가로활의 유무를 평가하였다. 일정한 부위로 측정하기 위해 발배뼈 부위에 마킹을 하였다. 실험대상자는 앉은 상태에서 평가를 시작했다. 이 때 발의 정렬 상태는 안쪽번짐과 가쪽번짐 없이 중립자세(neutral position)를 취하였다. 앉은 상태에서 지면으로부터 발배뼈의 높이를 측정하였다. 동일한 실험대상자가 앉 은 자세에서 측정된 발배뼈의 위치가 선 자세를 취했을 때 얼마나 내 려가는지를 자를 이용해 두 번을 측정해서 평균 내였다. 발배뼈 하강 검사 양성 그룹은 앉은 상태에서의 발배뼈의 높이가 선 자세로 바뀌 었을 때 떨어지는 높이가 $1.5 \mathrm{~cm}$ 이상인 경우이다(Figure 1). 발배뼈 하 강 검사 음성 그룹은 앉은 상태에서의 발배뼈의 높이가 선 자세로 바 뀌어 체중지지를 하는 동안에 떨이지는 높이가 $1 \mathrm{~cm}$ 미만인 경우이 다(Figure 2). ${ }^{6}$
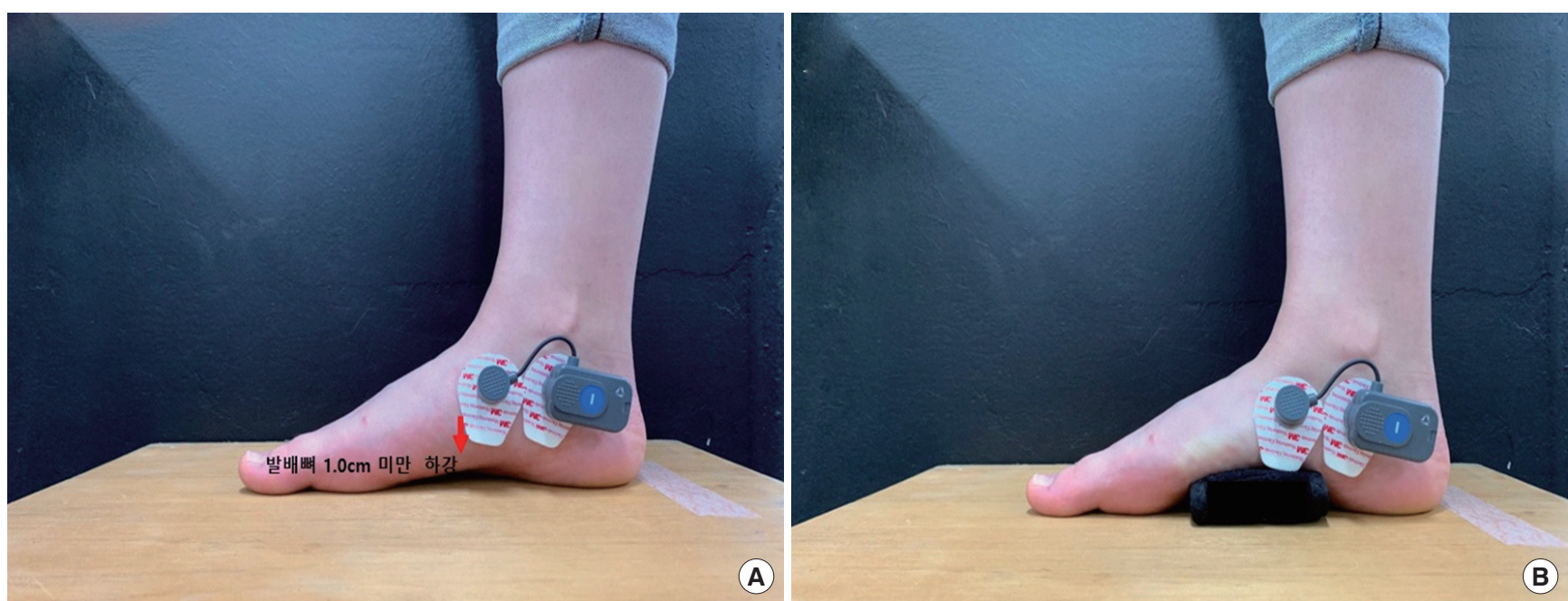

A)

3) 측정도구

(1) 엄지벌림근 초음파 측정

해당근육의 정확한 근힘살(muscle belly)을 파악하기 위해서 초음파 (Q30, SG Healthcare Co., Ltd., Seoul, Korea)에 연결된 7.5 MHz linear 도 자를 이용하여 확인하였다. 초음파를 통해 정확하게 확인한 부위에 팬으로 표시를 한 후, 근전도 패치 부착을 위해 초음파 겔을 제거하 였다. 엄지벌림근의 마킹 위치는 발배뼈에서부터 아래로 $2 \mathrm{~cm}$ 위치로 정하였다.

\section{(2) 엄지벌림근 근활성도 측정}

EMG-feedback (wireless EMG System 1000, BTS, Italy) 장비를 이용하여 근활성도 측정을 하였다. 엄지벌림근의 근활성도를 분석하기 위해 전용 소프트웨어를 사용하였다. 근전도 패치를 부착하는 위치는 저 항을 최소화하기 위하여 면도를 수행한 후, 알코올 솜을 이용하여 소 독하였다. 2 개의 전극은 근섬유 방향과 평행하게 부착하였다. 여과필 터 $(60 \mathrm{~Hz})$, 대역 통과 필터 $(20-450 \mathrm{~Hz})$, 표본추출률 $(1,024 \mathrm{~Hz})$ 로 설정하 였고, 수집된 근활성도는 RMS 처리하였다. \%MVIC (maximal voluntary isometric contraction)방법을 이용하여 표준화하였다. 엄지발가락 을 최대한 벌림 동작을 취하고 있을 때, 엄지발가락 첫마디뼈(proximal phalanx) 중앙에 측정자의 손을 이용해서 저항을 제공하였다. $\% \mathrm{MVIC}$ 측정을 위해 총 3 번의 측정을 실시하였다 (Table 1).

Figure 2. The group without navicular drop sign (A) without external arch support, (B) with external arch support

Table 1. The muscle activity of the abductor hallucis

$(\% \mathrm{MVIC})$

\begin{tabular}{|c|c|c|c|c|}
\hline \multirow{2}{*}{ Abductor hallucis } & \multicolumn{2}{|c|}{ Mean \pm SD } & \multirow{2}{*}{$\mathrm{F}$} & \multirow{2}{*}{$\mathrm{p}$} \\
\hline & Without external arch support & With external arch support & & \\
\hline The group with navicular drop sign & $15.42 \pm 5.11$ & $23.93 \pm 6.21$ & -6.82 & $<0.05^{*}$ \\
\hline The group without navicular drop sign & $17.64 \pm 4.42$ & $18.19 \pm 3.85$ & -3.74 & $>0.05$ \\
\hline
\end{tabular}

SD: standard deviation, MVIC: maximal voluntary isometric contraction, * significant difference between without- and with arch support. 
(3) 엄지벌림근 근력측정

엄지벌림근의 등척성 최대 수축을 통해 나오는 힘을 스마트케마 시 스템(Smart KEMA Pulling Sensor, Factorial Holdings Co., Ltd., Seoul, Korea)을 이용한장력 장치로 측정하였다(Figure 3).

장력 센서에 연결된 얇은 스트랩을 엄지발가락의 발허리발가락관 절(metatarsophalangeal joint)과 발가락뼈사이관절 (interphalangeal joint) 사이, 즉 엄지발가락 첫마디뼈(proximal phalanx) 중앙에 위치해 서 걸었다. 엄지벌림근만의 선택적 근력 측정을 위해서 첫번째 발허 리뼈(metatarsal bone)를 비탄력벨트로 고정함으로써 발목관절의 모 음(adduction)을 방지하였다. 그리고 측정오차를 최소화 하기 위해서 스트랩에 접촉된 발가락관절 부위는 마킹을 하였다. 선 자세에서 엄 지발가락의 중립자세에서 스트랩의 길이를 조절하였다. 스마트케마 시스템을 이용한 장력 장치는 최대 100 키로까지 측정가능하며, 0.1 키 로 미만의 정확성과 0.1 키로 미만의 소실이 있었다. 발의 가로활에 외 부적 지지를 제공하기 위해서, 앉아 있는 상태에서 측정된 발배뼈의 높이와 동일하게 구성된 아치서포트를 실험 대상자에게 제공하였다 (Table 2). ${ }^{6}$

\section{3. 통계분석}

통계분석을 위해 SPSS software (ver. 18.0, SPSS IL, Chicago)가 사용되었 다. 측정데이터의 정규분포를 확인하였다. 일표본 kolmogorov-

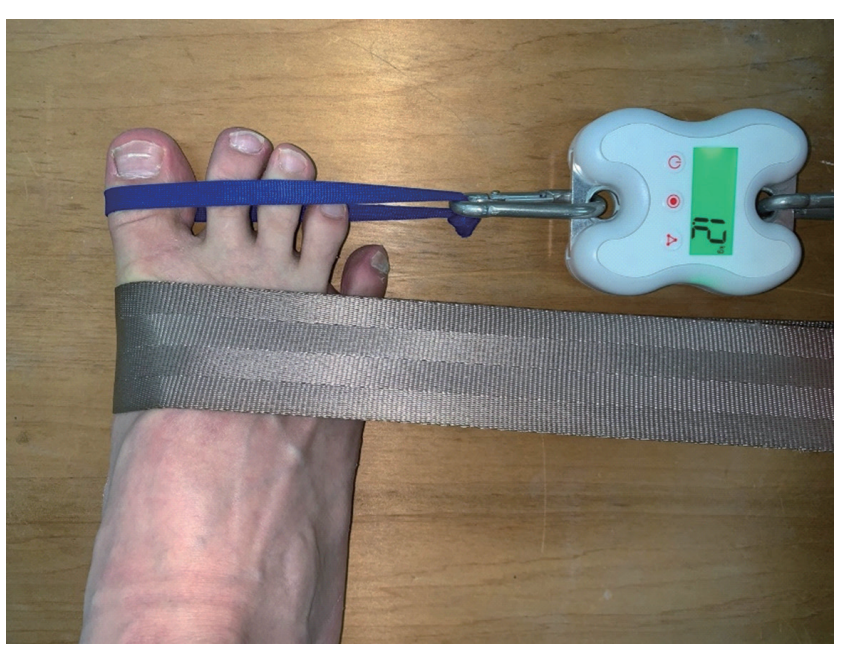

Figure 3. The measurement of muscle strength of the abductor hallucis smirnov 검정을 통해 측정데이터의 정규 분포를 확인하였다. 두 그룹 간(발배뼈 하강 양성그룹 vs 음성그룹) 사이의 차이와 그룹 내(외부 적 지지제공 vs 비제공) 사이에 통계학적으로 유의한 차이가 있는지 확인하기 위하여 Two-way mixed model analysis of variance (ANOVA) 이 사용되었다. 통계학적 유의 수준은 0.05 로 정하였다.

\section{결 과}

두 그룹 간(발배뼈 하강 양성그룹 vs 음성그룹) 사이의 차이와 그룹 내(외부적 지지제공 vs 비제공) 요인의 주효과 상에 유의한 차이가 있 었고, 상호작용 효과는 존재하지 않았다( $\mathrm{p}>0.05)$. 따라서 주효과를 통해각 독립변수간에 효과에 대해서 확인하였다.

우선 발배뼈 하강 검사를 통해 발배뼈 하강검사 양성그룹에서는 $1.65 \pm 0.11 \mathrm{~cm}$ 의 하강을 보였고, 음성그룹에서는 $0.59 \pm 0.19 \mathrm{~cm}$ 의 하강 을 보였다.

발배뼈 하강 검사 양성그룹에서 엄지벌림근의 근력과 근활성도에 외부적 지지를 제공해 주었을 때 통계학적으로 유의한 증가를 보였 다(Table 1,2).

발배뼈 하강 검사 음성그룹에서는 외부적 지지 제공 여부에 따라 엄지벌림근의 근력과 근활성도에 통계학적 유의한 차이를 보이지 않 았다(Table 1,2).

\section{고 찰}

엄지벌림근의 충분한 근력은 무지 외반증(hallux valgus) 증상이 있거 나, 편평발 증상 그리고 만성적 발허리관절 재활을 위해 중요한 요소 이다. 그리고 선 자세 균형을 향상시키기 위해서도 중요하다고 볼 수 있다. ${ }^{16}$ 그러나 임상적으로 엄지벌림근의 근력 평가를 수행하면서, 발 의 가로활에 대한 고려를 하지 않고 있다. 이 연구에서는 발배뼈 하강 검사를 통해서 평가된 가로활이 정상인 그룹과 비정상인 그룹을 구 별하였고, 선 자세에서 외부적인 가로활 지지를 제공해주었을 때의 여부가 엄지벌림근의 근력과 근활성도에 영향을 미치는지에 대한차 이를 비교하고자 하였다.

엄지벌림근의 근력은 발배뼈 하강 검사 양성그룹에서 외부적 지지 가 없을 때보다 제공되었을 때 상당히 큰 증가를 보였다 $(\mathrm{p}<0.05)$. 그

Table 2. The strength of the abductor hallucis

$(\mathrm{kg})$

\begin{tabular}{|c|c|c|c|c|}
\hline \multirow{2}{*}{ Abductor hallucis } & \multicolumn{2}{|c|}{ Mean $\pm S D$} & \multirow{2}{*}{$\mathrm{F}$} & \multirow{2}{*}{$\mathrm{p}$} \\
\hline & Without external arch support & With external arch support & & \\
\hline The group with navicular drop sign & $1.35 \pm 0.48$ & $2.65 \pm 0.51$ & -10.11 & $<0.05^{\star}$ \\
\hline The group without navicular drop sign & $2.23 \pm 0.53$ & $2.76 \pm 0.47$ & -1.66 & $>0.05$ \\
\hline
\end{tabular}

SD: standard deviation, *significant difference between without- and with arch support. 
러나 엄지벌림근의 근력은 발배뼈 하강 검사음성그룹에서는 외부적 지지에 따른 통계학적 유의한 차이를 보이지 않았다( $\mathrm{p}>0.05)$. 발배뼈 하강 양성그룹에서 엄지벌림근의 근력과 근활성도 증가는 외부적 지 지가 제공되면서 향상되었는데, 이것은 발의 가로활이 형성되면서 엄 지벌림근이 잘 수축할 수 있는 정렬이 형성된 것으로 생각할 수 있다. 그 반대로 가로활이 형성되지 않은 상태에서는 상대적으로 근활성 도와 근력이 떨어진 것을 확인할 수 있었다. 결과적으로 엄지벌림근 이 이상적으로 수축할 수 있는 정렬에서 근활성도가 증가했고, 그 요 소가 엄지벌림근 근력 증가에 긍정적 영향을 미쳤다는 것으로 생각 할수 있다.

외부적인 지지 제공 여부에 따른 엄지벌림근 근력과 근활성도 차 이에 대해서 다음과 같이 몇가지 이유를 설명하고자 한다. 첫번째, 생 체역학적인 요소로 설명될 수 있다. 선행 연구에서는 발가락의 움직 임 동안에 발의 안정성이 내재근 활성화에 기여하게 되는데, 특히 엄 지벌림근은 발허리뼈 중앙에 부착되어 있기 때문에 내재근 활성화로 부터 더 영향을 받는다는 것이다. ${ }^{6,17}$ 다른 선행 연구에서는 엄지벌림 근의 근활성도가 짧은발 운동(short foot exercise)에 비해서 발가락 벌 림 운동 시 더 증가한다고 보고되었다. ${ }^{1718}$ 이 연구결과에서처럼 발의 가로활이 엄지벌림근의 근력과 근활성도에 영향을 미친다고 볼 수 있다. ${ }^{19}$

두번째, 길이장력관계(length tension relationship)로 설명될 수 있 다. 엄지벌림근은 첫번째 발허리뼈 관절에서 매우 중요한 역할을 하는, 특히 한쪽 다리로 선 자세에서 안정화 역할을 할 수 있다. ${ }^{6}$ 선 자세에서 발의 가로활이 체중 지지가 되었을 때 중력에 반하여 발 이 뒤침 되는 것을 막아줄 수 있다. ${ }^{6,20}$ 그러나 발배뼈 하강 양성그룹 에서 발의 안정화를 위해서는 불충분한 가로활 때문에 선 자세에 서 체중 지지 시 발배뼈가 밑으로 떨어지는 것으로 인해 발목뼈에 엎침이 유발되고, 또 이것은 엄지벌림근육이 늘어난 자세가 된다. 결과적으로 발의 내재근들과 엄지벌림근이 상호수축하기 어려움 을 의미한다. ${ }^{20,21}$ 외부적으로 가로활을 지지해주는 것은 선 자세에 서 엄지벌림근과 발의 내재근이 서로 공동수축(co-contraction) 할 수 있는 효과적인 정렬을 만들어 주고, 이것이 발의 안정성을 큰 기 여를 할 수 있다. ${ }^{20}$ 이러한 외부적 가로활 지지는 선 자세에서 발배 뼈의 하강을 최소화해 줌으로써, 체중지지를 한 발목뼈가 엎침이 되는 것을 최소화 시켜주고, 결과적으로 엄지벌림근이 효과적으 로 수축할 수 있는 발의 정렬 위치를 확보해 준다는 것에 의미가 있 다. 엄지벌림근이 효과적으로 수축할 수 있는 발의 이상적인 정렬 이 엄지벌림근의 근활성도가 유의하게 증가할 수 있는 중요한 요소 라고 볼 수 있다. 이에 따른 근활성도의 증가는 엄지벌림근의 근력 증가에 영향을 미친 것이라고 볼 수 있다.

발배뼈 하강 검사 양성그룹은 선 자세에서 엄지벌림근이 외부적
지지가 제공되었을 때 근활성도와 근력이 향상되었다는 것을 통해, 엄지벌림근의 기능을 종합적으로 평가하기 위해 발배뼈 하강 검사 를 통한 가로활 유무에 대한 고려가 필요하다.

이 연구는 몇가지 제한점이 있다. 첫번째 젊은 성인 대상자가 참여 하여 실험이 진행되었다. 추후 연구에서는 노인 계층의 엄지벌림근 근력과 근활성도가 가로활에 영향을 받는지에 대한 조사가 필요하 다. 두번째, 발배뼈 하강 테스트에 대한 세분화된 단계를 적용하지 않 았다. 추후 연구에서는 발배뼈가 떨어지는 단계에 따른 엄지벌림근 활성도 차이 비교가 필요하다. 세번째, 가로활의 외부적 지지를 위해 일관된 높이의 지지물을 사용하였다.

\section{ACKNOWLEDGEMENTS}

본 연구는 한국연구재단 기초과학연구 (생애첫연구)의 연구비 지원 을 받았음(No. 2017R1C1B5076172).

\section{REFERENCES}

1. Kisner C, Colby LA. Therapeutic exercise: foundations and techniques. 6th ed., Philadelphia, Fa Davis. 2012

2. ArinciIncel N, Genc H, Erdem HR et al. Muscle imbalance in hallux valgus: an electromyographic study. AmJ Phys Med Rehabil. 2003; 82(5): 345-9.

3. Sahrmann SA. Diagnosis and treatment of movement impairment syndromes. St. Louis, Mosby. 2001

4. Ekstrom RA, Donatelli RA, Carp KC. Electromyographic analysis of core trunk, ankle, and thigh muscles during 9 rehabilitation exercises. J Orthop Sports Phys Ther. 2007:37(12);754-62.

5. Leetun DT, Ireland ML., Willson JD et al. Core stability measures as risk factors for lower extremity injury in athletes. Med Sci Sports Exerc. 2004;36(6):926-34

6. Sahrmann S. Movement system impairment syndromes of the extremities, cervical and thoracic spines-e-book. Amsterdam, Elsevier. 2010

7. Leinonen V, Kankaanpää M, Airaksinen O et al. Back and ankle extensor activities during trunk flexion/extension: effects of low back pain and rehabilitation. Arch Phys Med Rehabil. 2000;81(1): 32-7.

8. Coughlin MJ. Hallux valgus. J Bone Joint Surg Am. 1996;78(6):932-66.

9. Neumann DA. Kinesiology of the musculoskeletal system-e-book: foundations for rehabilitation. Amsterdam, Elsevier. 2006

10. Coughlin MJ, Saltzman CL, Nunley JA, Angular measurements in the evaluation of hallux valgus deformities: a report of the ad hoc committee of the american orthopaedic foot \& ankle society on angular measurements. Foot Ankle Int. 2002;23(1):68-74.

11. Mann RA, Coughlin MJ. Adult hallux valgus, surgery of the foot and ankle. 7th ed. St. Louis: Mosby, 1999.

12. Jung DY, Kim MH, Koh EK et al, A comparison in the muscle activity of the abductor hallucis and the medial longitudinal arch angle during toe curl and short foot exercises. Phys Ther Sport. 2011;12(1):30-5.

13. Kendall FP, McCreary EK, Provance PG et al. Muscles: testing and func- 
tion, with posture and pain, 5th ed. Philadelphia, Lippincott Williams \& Wilkins. 2005.

14. Wülker N, Mittag F, The treatment of hallux valgus. Dtsch Arztebl Int. 2012;109(49):857-67.

15. Bolgla LA, Uhl TL. Electromyographic analysis of ankle rehabilitation exercises in a group of healthy subjects. J Orthop Sports Phys Ther. 2005;35(8):487-94.

16. Tehraninasr A, Saeedi H, Forogh B et al. Effects of insole with toe-separator and night splint on patients with painful hallux valgus: a comparative study. Prosthet Orthot Int. 2008;32(1): 79-83.

17. Kim MH, Kwon OY, Kim SH et al. Comparison of muscle activities of abductor hallucis and adductor hallucis between the short foot and toe- spread-out exercises in subjects with mild hallux valgus. J Back Musculoskelet Rehabil. 2013;26(2):163-8.

18. Heo HJ, Koo YM, Yoo WG, Comparison of selective activation of the abductor hallucis during various exercises. J Phys Ther Sci. 2011;23(6): 915-8

19. Lee JE, Park GH, Lee YS et al. A comparison of muscle activities in the lower extremity between flat and normal feet during one-leg standing. J Phys Ther Sci. 2013;25(9):1059-61.

20. Brenner E. Insertion of the abductor hallucis muscle in feet with and without hallux valgus. Anat Rec. 1999;254(3):429-34.

21. Maughan RJ, Watson JS, Weir J. Strength and cross-sectional area of human skeletal muscle. J Physiol. 1983;338:37-49. 